\title{
Gastric Neuroendocrine Tumor pT4 TNM Finding v8
}

National Cancer Institute

\section{Source}

National Cancer Institute. Gastric Neuroendocrine Tumor pT4 TNM Finding v8. NCI

Thesaurus. Code C135040.

Gastric neuroendocrine tumor invading visceral peritoneum (serosa) or other org ans or adjacent structures. (from AJCC 8th Ed.) 